\title{
A randomised controlled study: efficacy of ICU nursing risk management combined with the cluster nursing model and its effect on quality of life and inflammatory factor levels of patients with acute respiratory distress syndrome and ventilator-associated pneumonia
}

\author{
Zhaojia Xü ${ }^{1 \#}$, Juan Chen ${ }^{2 \#}$, Rongjun $\mathrm{Xu}^{3}$ \\ ${ }^{1} \mathrm{ICU}$, Wuhan Jinyintan Hospital, Wuhan, China; ${ }^{2}$ Department of Surgical, Wuhan Jinyintan Hospital, Wuhan, China; ${ }^{3}$ Supply Unit in Hospital, \\ Wuhan Jinyintan Hospital, Wuhan, China \\ Contributions: (I) Conception and design: Z Xu; (II) Administrative support: R Xu; (III) Provision of study materials or patients: Z Xu; (IV) Collection \\ and assembly of data: Z Xu, J Chen; (V) Data analysis and interpretation: R Xu; (VI) Manuscript writing: All authors; (VII) Final approval of \\ manuscript: All authors. \\ \#These authors contributed equally to this work. \\ Correspondence to: Rongjun Xu. Supply Unit in Hospital, Wuhan Jinyintan Hospital, No. 1 Yintan Road, Dongxihu District, Wuhan 430013, China. \\ Email: nafujif7@163.com.
}

\begin{abstract}
Backgroundk The purpose was to investigate the effect on quality of life and inflammatory factor levels of patients with acute respiratory distress syndrome (ARDS) and ventilator-associated pneumonia (VAP).

Methods: A total of 110 ARDS patients with VAP were randomly divided into an experimental group and control group. The control group received routine nursing while the experimental group received ICU nursing risk management combined with the cluster nursing model to compare the clinical efficacy in the two groups of patients.
\end{abstract}

Results: There were no significant differences in general information $(\mathrm{P}>0.05)$. The total clinical effective rate of patients in the experimental group was significantly higher than that of the control group $(\mathrm{P}<0.05)$. The Acute Physiology and Chronic Health Evaluation (APACHE II) scores of all patients after nursing were significantly lower than those before nursing $(\mathrm{P}<0.001)$, and the APACHE II score in the experimental group after nursing was significantly lower than that in the control group $(\mathrm{P}<0.001)$. The interleukin-8 (IL-8), interleukin-6 (IL-6), and tumor necrosis factor- $\alpha$ (TNF- $\alpha$ ) levels of all patients after nursing were significantly lower than those before nursing $(\mathrm{P}<0.001)$, and the levels in the experimental group after nursing were significantly lower than those in the control group $(\mathrm{P}<0.001)$. The vital capacity (VC), total lung capacity (TLC), and forced expiratory volume 1 second $\left(\mathrm{FEV}_{1}\right)$ /forced vital capacity (FVC) levels of all patients after nursing were significantly higher than those before nursing $(\mathrm{P}<0.001)$, and the levels in the experimental group after nursing were significantly higher than those in the control group $(\mathrm{P}<0.001)$. The MOS 36-item short form health survey (SF-36) scores of all patients after nursing were significantly higher than those before nursing $(\mathrm{P}<0.001)$, and the scores in the experimental group after nursing was higher than that in the control group $(\mathrm{P}<0.001)$.

Conclusions: ICU nursing risk management combined with the cluster nursing model can effectively and significantly reduce inflammatory reactions, improve pulmonary function, and enhance the quality of life of ARDS patients with VAP, making it worthy of promotion and application.

Trial registration: Chinese Clinical Trial Registry ChiCTR2100048112.

Keywords: Risk management (ICU nursing risk management); cluster nursing; acute respiratory distress syndrome (ARDS); ventilator-associated pneumonia (VAP); efficacy 
Submitted Apr 14, 2021. Accepted for publication Jul 22, 2021.

doi: 10.21037/apm-21-1192

View this article at: https://dx.doi.org/10.21037/apm-21-1192

\section{Introduction}

Acute respiratory distress syndrome (ARDS), a common respiratory disease, is mostly caused by severe trauma, infection, and other factors. Patients often show intractable hypoxemia and respiratory failure. ARDS is one of the serious respiratory diseases endangering human life and health $(1,2)$. ARDS patients are mostly dependent on mechanical ventilation, and ventilator-associated pneumonia (VAP) is a common complication of mechanical ventilation. Clinical studies have found that the incidence of VAP in ARDS patients is $24.6-27.5 \%$ (3). VAP will aggravate the condition of patients, prolong the treatment time, and increase the pain of patients. Therefore, effective clinical nursing is of great significance to reduce the incidence of VAP and improve the clinical efficacy of treatment. The condition of ICU patients is complex and variable, and their lives are in danger. Many factors are involved in the changes in patients' conditions, which lead to great difficulty in clinical nursing and a high requirement for professional technology. ICU nursing risk management is an emerging management method to study the occurrence rule of ICU risk in patients and carry out risk control, which reduces the risk of clinical adverse events through risk identification, risk assessment, and risk evaluation, mobilizing the work enthusiasm of medical staff and establishing a good nursepatient relationship (4-6). Cluster nursing is a nursing concept based on evidence-based medicine, which can provide comprehensive and comfortable health services for patients with severe diseases, minimize the suffering of patients, and improve prognosis $(7,8)$. Based on this, in order to further explore the effect of ICU nursing risk management combined with the cluster nursing model on the quality of life and inflammatory factor levels of ARDS patients with VAP, 110 ARDS patients with VAP treated in Wuhan Jinyintan Hospital from June 2018 to June 2019 were selected as the study subjects, and data were summarized and reported as follows. We present the following article in accordance with the CONSORT reporting checklist (available at http://dx.doi.org/10.21037/ apm-21-1192) (9).

\section{Methods}

\section{General information}

The study was a two-parallel study. A total of 110 ARDS patients with VAP treated in Wuhan Jinyintan Hospital from June 2018 to June 2019 were selected as the study subjects, and randomly divided into the experimental group and control group, with 55 cases in each group (Figure 1). The allocation ratio is $1: 1$. The study was conducted in accordance with the Declaration of Helsinki (as revised in 2013). The study was approved by ethics board of Wuhan Jinyintan Hospital (No. 2018051207).

\section{Inclusion criteria}

(I) Compliance with the diagnostic criteria of ARDS; (II) mechanical ventilation time $(\geq 48 \mathrm{~h})$ and the occurrence of VAP; (III) complete clinical data; (IV) this study was approved by the ethics committee of Wuhan Jinyintan Hospital, and the patients and their families knew the purpose and process of this experimental study, and signed the informed consent.

\section{Exclusion criteria}

(I) Expected survival time less than 3 months; (II) combination with other respiratory diseases; (III) cognitive impairment such as mental disorders; (IV) acute hemorrhage and intracranial hypertension.

\section{Study methods}

The control group received routine nursing. The patients were placed in a semi-recumbent position, and their oral cavity was cleaned with chlorhexidine solution. A catheter was placed at the glottis to drain the secretions. ICU environmental nursing was implemented through regular disinfection every day, maintenance of indoor temperature and humidity, regular replacement of sterile liquid of humidifiers and threaded tubes of ventilators, and timely cleaning of condensate water to avoid backflow. Nurses paid 
attention to personal hygiene and protected themselves.

The experimental group received ICU nursing risk management combined with the cluster nursing model.

ICU nursing risk management: (I) nursing management teams were established, including ICU head nurses and specialist nurses with rich clinical experience and over 5 years of practice. As team leaders, head nurses carried out ICU nursing risk management training to improve the professional skills of other team members. (II) The patients were informed of VAP-related knowledge so that they could correctly understand VAP and eliminate negative emotions, improving treatment compliance (10). The vital signs of patients were closely monitored, and nursing for the prevention of infection was implemented through aseptic operation and disinfection. (III) Attention was paid to practical operation to ensure the standardization of clinical operation in nursing staff. A corresponding assessment mechanism was formulated to implement standardized operation, fundamentally reducing the incidence of VAP. (IV) The risk management awareness of nursing staff was strengthened through encouraging them to learn ICU nursing knowledge in their spare time to improve professional skills $(11,12)$.

Cluster nursing model: (I) ward management was implemented through regular disinfection of ICU wards every day to keep the air fresh, strictly limiting the number of people and visits, and advising visitors to carry out disinfection of the whole body and wear insulated clothing when entering ICU wards. (II) Oral nursing, nasal feeding, and postural nursing were strengthened. The patients were placed in a semi-reclining position, and kept the same posture 30 minutes after the completion of nasal feeding to promote gastric emptying to avoid reflux and inhalation of gastric contents. As dental plaque is an important factor that induces VAP, oral nursing of patients was implemented 3-4 times every week after appropriate cleaning solution was selected according to the $\mathrm{PH}$ value of the patient's oral cavity. (III) For airway management, the nursing staff regularly turned over the patients' bodies every day, tapped the back to drain sputum, used a humidification system to humidify the sputum in their airway, and sucked sputum by flushing and negative pressure drainage, so as to reduce the damage to tracheal mucosa.

\section{Evaluation indexes}

Efficacy evaluation (primary outcome): after nursing, the respiratory secretions of patients decreased greatly, and body temperature and the number of leukocytes returned to normal levels compared with that before nursing, indicating that it was markedly effective. The clinical signs of patients did not change significantly or even worsened, which was ineffective. Total effective rate $=$ markedly effective rate + effective rate

The Acute Physiology and Chronic Health Evaluation (APACHE II) (13) was used to evaluate the severity of disease before and after nursing (second outcome). The scale included an acute physiology score, chronic health score, and age score, with a total score of 100 points. The higher the score was, the more serious the condition of the patients.

A total of $3 \mathrm{~mL}$ of fasting venous blood was collected from the two groups of patients before and after nursing (primary outcome). The enzyme-linked immunosorbent assay (ELISA) was used to measure the levels of interleukin-8 (IL-8), interleukin-6 (IL-6), and tumor necrosis factor- $\alpha$ (TNF- $\alpha$ ). The kit was purchased from Suzhou Comin Biotechnology Co., Ltd. and measurements were performed strictly according to the kit instructions.

A pulmonary function detector (manufacturer: Jinan Laibao Medical Devices Co., Ltd.) was used to detect the vital capacity (VC), total lung capacity (TLC), forced expiratory volume 1 second $\left(\mathrm{FEV}_{1}\right)$, and forced vital capacity (FVC) in the two groups of patients before and after nursing. Then, the $\mathrm{FEV}_{1} / \mathrm{FVC}$ was calculated (second outcome).

The MOS 36-item short form health survey (SF-36) (14) was used to evaluate the quality of life of patients in the two groups before and after intervention. The scale had 36 scoring items, with a total score of 100 points. The higher the score was, the higher the quality of life of the patients (second outcome).

\section{Statistical methods}

The experimental data were statistically analyzed and processed by SPSS 20.0 software. GraphPad Prism 6 (GraphPad Software, San Diego, CA, USA) was used to construct the figures of the data. Count data were tested by the $\chi^{2}$ test and expressed as $\mathrm{n}(\%)$. Measurement data were assessed by the $t$-test and expressed as $(\bar{x} \pm s)$. Differences were statistically significant when $\mathrm{P}<0.05$.

\section{Results}

\section{Comparison of clinical data between the two groups of patients}

There were no significant differences in gender ratio, age, 
Table 1 Comparison of clinical data between the two groups of patients

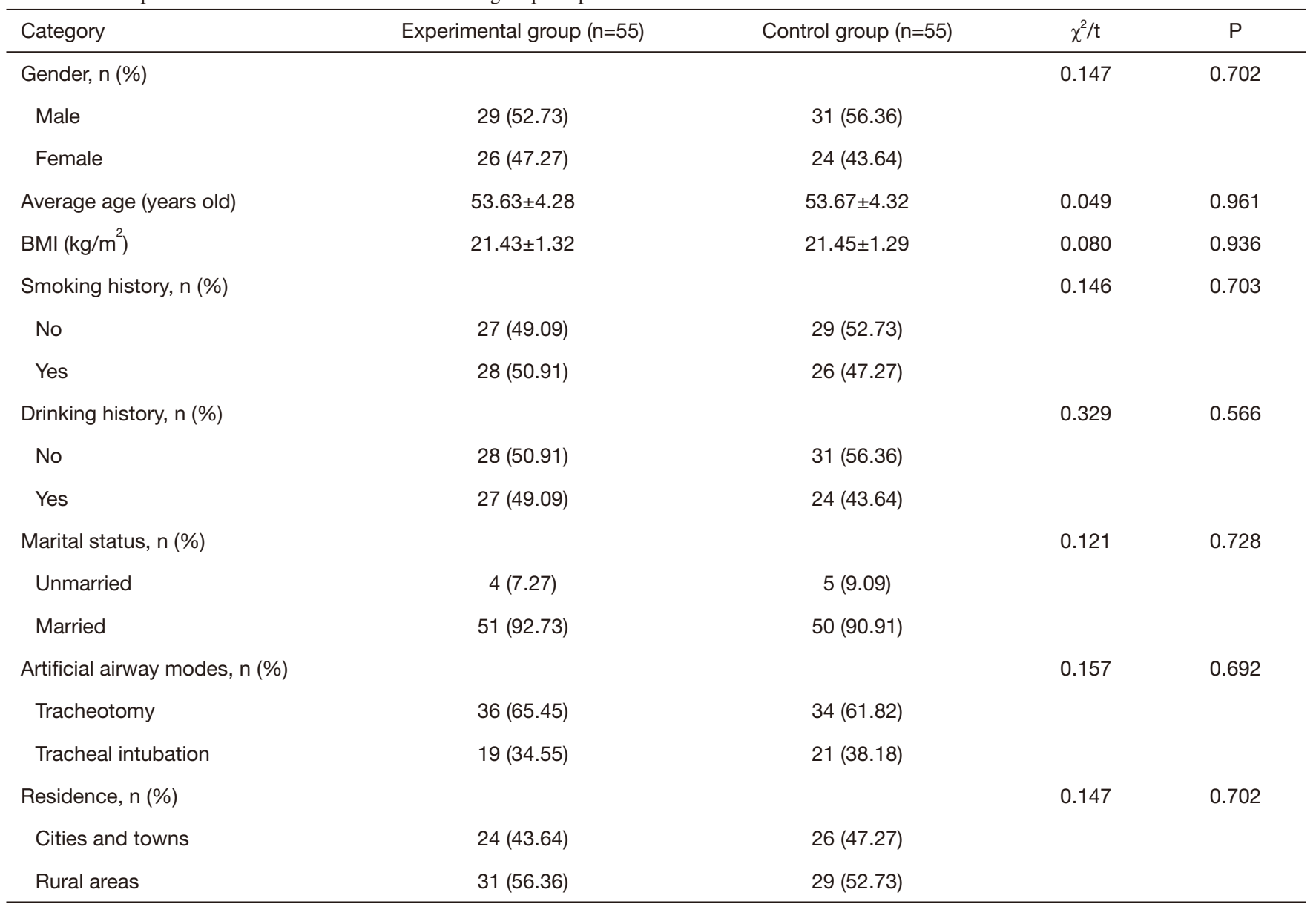

BMI, smoking history, drinking history, marital status, artificial airway modes, and residence between the two groups of patients $(\mathrm{P}>0.05)$, indicating that they were comparable, as shown in Table 1 and Figure 1.

\section{Comparison of clinical efficacy between the two groups of patients}

The total clinical effective rate of patients in the experimental group was significantly higher than that of the control group $(\mathrm{P}<0.05)$, as shown in Table 2.

\section{Comparison of APACHE II scores between the two groups of patients before and after nursing}

The APACHE II scores of patients in both groups after nursing were significantly lower than those before nursing $(\mathrm{P}<0.05)$, and the APACHE II score in the experimental group after nursing was significantly lower than that in the control group $(\mathrm{P}<0.05)$, as shown in Figure 2.

\section{Comparison of inflammatory factor levels between the two groups of patients before and after nursing}

The IL-8, IL-6, and TNF- $\alpha$ levels of patients in both groups after nursing were significantly lower than those before nursing $(\mathrm{P}<0.05)$, and the levels in the experimental group after nursing were significantly lower than those in the control group $(\mathrm{P}<0.05)$, as shown in Table 3.

\section{Comparison of pulmonary function indexes between the two groups of patients before and after nursing}

The VC, TLC, and $\mathrm{FEV}_{1} / \mathrm{FVC}$ levels of patients in both groups after nursing were significantly higher than those before nursing $(\mathrm{P}<0.05)$, and the levels in the experimental 


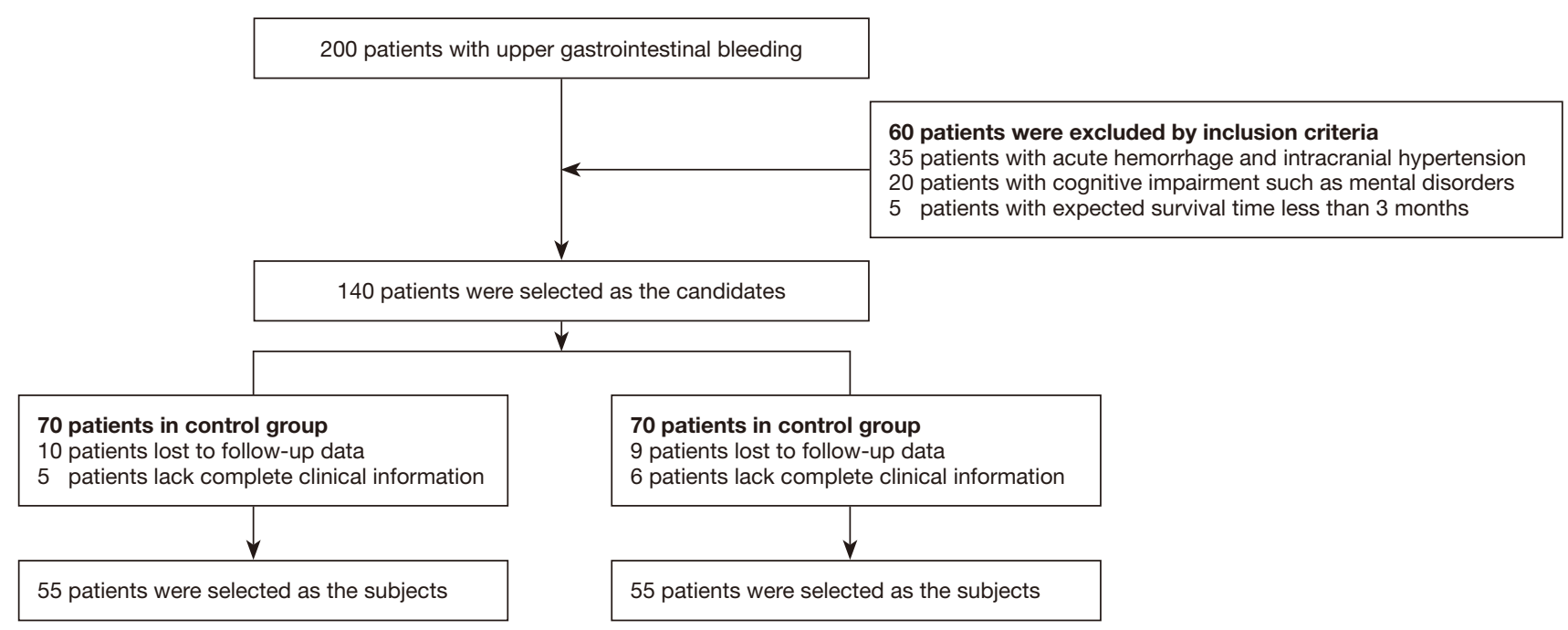

Figure 1 Study profile.

Table 2 Comparison of clinical efficacy between the two groups of patients [n (\%)]

\begin{tabular}{|c|c|c|c|c|c|}
\hline Group & $\mathrm{N}$ & Markedly effective & Effective & Ineffective & Total effective rate \\
\hline Control group & 55 & $21(38.18)$ & $24(43.64)$ & $10(18.18)$ & $45(81.82)$ \\
\hline$\chi^{2}$ & & & & & 4.274 \\
\hline$P$ & & & & & 0.039 \\
\hline
\end{tabular}

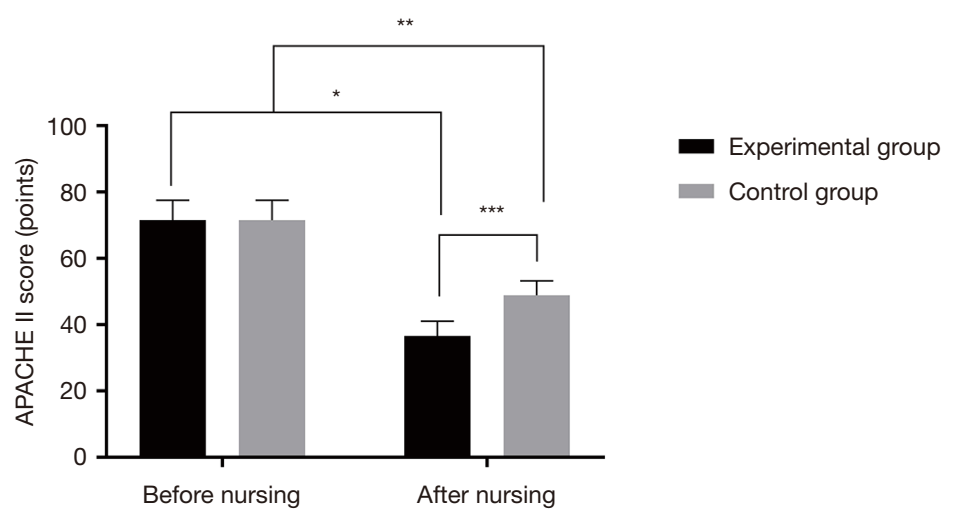

Figure 2 Comparison of APACHE II scores between the two groups of patients before and after nursing $(\bar{x} \pm \mathrm{s})$. The abscissa represents before nursing and after nursing, and the ordinate represents the APACHE II score (points). The APACHE II score of patients in the experimental group was $67.24 \pm 8.56$ points before nursing and $33.49 \pm 6.24$ points after nursing. The APACHE II score of patients in the control group was $67.28 \pm 8.53$ points before nursing and $45.73 \pm 6.21$ points after nursing. ${ }^{*}$ indicated that there was a significant difference in APACHE II scores of patients in the experimental group before and after nursing $(\mathrm{t}=23.629, \mathrm{P}=0.000)$; ${ }^{* *}$ indicated that there was a significant difference in APACHE II scores of patients in the control group before and after nursing $(\mathrm{t}=15.147, \mathrm{P}=0.000) ;{ }^{* * *}$ indicated that there was a significant difference in APACHE II scores between the two groups of patients after nursing ( $t=10.311, \mathrm{P}=0.000)$. APACHE II, Acute Physiology and Chronic Health Evaluation. 
Table 3 Comparison of inflammatory factor levels between the two groups of patients before and after nursing $(\bar{x} \pm \mathrm{s}, \mathrm{pg} / \mathrm{mL})$

\begin{tabular}{lccccc}
\hline Group & $\mathrm{N}$ & Time & TNF- $\alpha$ & \multicolumn{1}{c}{ IL-8 } & IL-6 \\
\hline Experimental group & 55 & Before nursing & $84.32 \pm 4.54$ & $89.41 \pm 7.31$ & $65.23 \pm 4.29$ \\
& & After nursing & $33.28 \pm 4.19$ & $35.52 \pm 6.21$ & $28.41 \pm 3.56$ \\
Control group & 55 & Before nursing & $84.35 \pm 4.52$ & $89.39 \pm 7.32$ & $65.26 \pm 4.31$ \\
& & After nursing & $54.21 \pm 4.23^{\star}$ & $54.72 \pm 6.19^{\star}$ & $41.58 \pm 3.47^{\star}$ \\
\hline
\end{tabular}

The inflammatory factor levels of patients in both groups after nursing were significantly lower than those before nursing. ${ }^{*}$ indicated the comparison between the experimental group and the control group $(\mathrm{P}<0.001)$. TNF- $\alpha$, tumor necrosis factor- $\alpha$; IL-8, interleukin-8; IL-6, interleukin-6.

Table 4 Comparison of pulmonary function indexes between the two groups of patients before and after nursing $(\bar{x} \pm \mathrm{s}, \%)$

\begin{tabular}{lccccc}
\hline Group & $\mathrm{N}$ & Time & VC & TLC & FEV $/$ FVC \\
\hline Experimental group & 55 & Before nursing & $80.26 \pm 4.21$ & $76.42 \pm 4.21$ & $84.64 \pm 3.26$ \\
& & After nursing & $89.54 \pm 4.17$ & $89.03 \pm 3.18$ & $94.21 \pm 3.17$ \\
Control group & 55 & Before nursing & $80.25 \pm 4.23$ & $76.39 \pm 4.19$ & $84.67 \pm 3.24$ \\
& & After nursing & $83.79 \pm 4.19^{*}$ & $86.41 \pm 3.22^{*}$ & $90.13 \pm 3.32^{*}$ \\
\hline
\end{tabular}

The pulmonary function indexes of patients in both groups after nursing were significantly higher than those before nursing. ${ }^{*}$ indicated the comparison between the experimental group and the control group $(\mathrm{P}<0.001)$. VC, vital capacity; TLC, total lung capacity; FEV ${ }_{1}$, forced expiratory volume 1 second; FVC, forced vital capacity.

group after nursing were significantly higher than those in the control group $(\mathrm{P}<0.05)$, as shown in Table 4 .

\section{Comparison of SF-36 scores between the two groups of patients before and after nursing}

The SF-36 scores of patients in both groups after nursing were significantly higher than those before nursing $(\mathrm{P}<0.05)$, and the SF-36 score in the experimental group after nursing was higher than that in the control group $(\mathrm{P}<0.05)$, as shown in Figure 3.

\section{Discussion}

Mechanical ventilation can effectively improve the ventilation conditions of ARDS patients, prevent the body from hypoxia, and create conditions for disease treatment (15). Studies have found that endotracheal intubation can bring normal bacterial flora of the upper airway into the lower airway, leading to respiratory tract infection. In addition, unclean hands and sputum suction tubes amongst other factors can also lead to flora into the respiratory tract of patients which induces infection (16-18). VAP is a common respiratory tract infectious disease in
ARDS patients, with a high incidence and mortality. The pathogenic risk of VAP is related to a variety of factors, such as the nutritional status of patients, complications, ward environment, and health standards of medical staff, amongst others. VAP can cause difficult weaning from mechanical ventilation in patients and prolong the ICU treatment time, resulting in increased treatment costs and threatening the lives and safety of patients. Therefore, effective nursing measures for inpatients with ARDS have important clinical significance in reducing the incidence of VAP and improving the prognosis of the disease.

Cluster nursing provides comprehensive and systematic nursing services for patients with severe diseases. Compared with traditional nursing, this nursing model pays more attention to the personal feelings of patients, which is more scientific, effectively improving the prognosis of ARDS patients with VAP and shortening the hospitalization time. ICU nursing risk management can significantly reduce the incidence of clinical risk events and nursepatient disputes, and reduce the incidence of $\operatorname{VAP}(19,20)$. Before implementing ICU nursing risk management, the nursing staff should firstly identify the various risk factors of patients during hospitalization, strive to improve professional knowledge, and enhance nursing skills to 


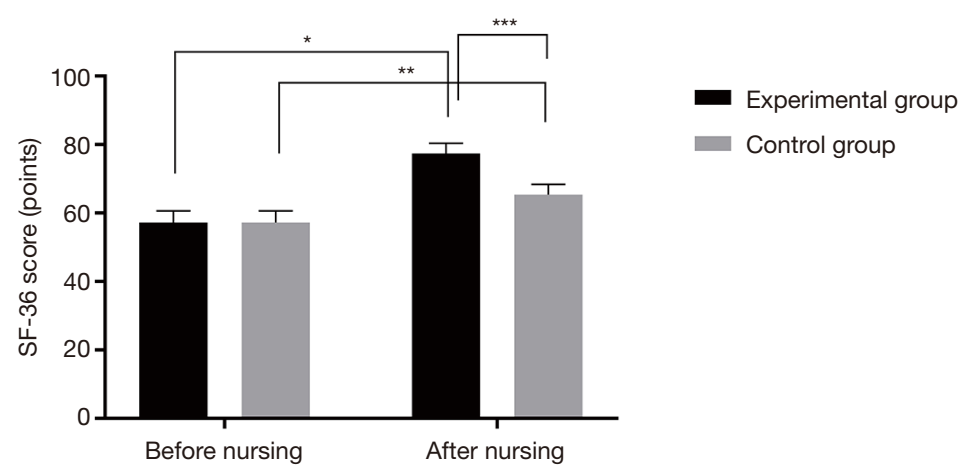

Figure 3 Comparison of SF-36 scores between the two groups of patients before and after nursing $(\bar{x} \pm \mathrm{s})$. The abscissa represents before nursing and after nursing, and the ordinate represents the SF-36 score (points). The SF-36 score of patients in the experimental group was $54.74 \pm 4.87$ points before nursing and $75.23 \pm 4.28$ points after nursing. The SF-36 score of patients in the control group was $54.78 \pm 4.85$ points before nursing and $63.16 \pm 4.35$ points after nursing. ${ }^{*}$ indicated that there was a significant difference in SF-36 scores of patients in the experimental group before and after nursing $(\mathrm{t}=23.438, \mathrm{P}=0.000)$; ** indicated that there was a significant difference in SF-36 scores of patients in the control group before and after nursing $(\mathrm{t}=9.539, \mathrm{P}=0.000)$; ${ }^{* *}$ indicated that there was a significant difference in $\mathrm{SF}-36$ scores between the two groups of patients after nursing $(\mathrm{t}=14.668, \mathrm{P}=0.000)$. SF-36, the MOS 36-item short form health survey.

implement standardized nursing operation and improve clinical efficacy. The APACHE II score is an important indicator that reflects the degree of acute physiological abnormalities in patients $(21,22)$. This study found that the APACHE II score in the experimental group after nursing was significantly lower than that in the control group $(\mathrm{P}<0.05)$, suggesting that the combined nursing model can significantly improve the condition of ARDS patients with VAP and improve the treatment effect. In addition, this study found that the SF-36 score in the experimental group after nursing was significantly higher than that in the control group $(\mathrm{P}<0.05)$. The reasons for this are firstly, before clinical nursing for ARDS patients with VAP, the nursing staff received training of professional knowledge to improve the level of nursing operation and enhance service awareness. Secondly, the risk management awareness of nursing staff was strengthened, and aseptic operation was strictly followed to reduce the occurrence of clinical infection events. In addition, since some patients were prone to anxiety due to a lack of understanding of their own disease, they were informed of VAP-related knowledge to correctly understand the disease and establish confidence in treatment. Makris et al. (23) pointed out in their study that after ICU nursing risk management combined with cluster nursing was adopted for patients with severe respiratory failure and VAP, the SF-36 score after nursing $(74.86 \pm 4.24)$ was significantly higher than $(63.28 \pm 4.27)$ of the reference group, indicating that the combined nursing model can significantly improve the quality of life of patients with mechanical ventilation, which is beneficial to treatment.

In conclusion, ICU nursing risk management combined with the cluster nursing model can effectively and significantly improve pulmonary function, reduce inflammatory reactions, enhance quality of life, and improve the prognosis of ARDS patients with VAP, making it worthy of promotion and application.

\section{Acknowledgments}

Funding: None.

\section{Footnote}

Reporting Checklist: The authors have completed the CONSORT reporting checklist. Available at https://dx.doi. org/10.21037/apm-21-1192

Trial Protocol: Available at https://dx.doi.org/10.21037/apm21-1192

Data Sharing Statement: Available at https://dx.doi. org/10.21037/apm-21-1192

Conflicts of Interest: All authors have completed the ICMJE uniform disclosure form (available at https://dx.doi. org/10.21037/apm-21-1192). The authors have no conflicts 
of interest to declare.

Ethical Statement: The authors are accountable for all aspects of the work in ensuring that questions related to the accuracy or integrity of any part of the work are appropriately investigated and resolved. The study was conducted in accordance with the Declaration of Helsinki (as revised in 2013). The study was approved by ethics board of Wuhan Jinyintan Hospital (No. 2018051207) and the patients and their families knew the purpose and process of this experimental study, and signed the informed consent.

Open Access Statement: This is an Open Access article distributed in accordance with the Creative Commons Attribution-NonCommercial-NoDerivs 4.0 International License (CC BY-NC-ND 4.0), which permits the noncommercial replication and distribution of the article with the strict proviso that no changes or edits are made and the original work is properly cited (including links to both the formal publication through the relevant DOI and the license). See: https://creativecommons.org/licenses/by-nc-nd/4.0/.

\section{References}

1. Oh TK, Song IA. Prior metformin therapy and 30day mortality in patients with acute respiratory distress syndrome: a nationwide cohort study. Ann Palliat Med 2020;9:903-11.

2. Leite TT, Gomes CAM, Valdivia JMC, Libório AB. Respiratory parameters and acute kidney injury in acute respiratory distress syndrome: a causal inference study. Ann Transl Med 2019;7:742.

3. Öztürk Birge A, Bedük T. The relationship of delirium and risk factors for cardiology intensive care unit patients with the nursing workload. J Clin Nurs 2018;27:2109-19.

4. Glimelius Petersson C, Ringdal M, Apelqvist G, et al. Diaries and memories following an ICU stay: a 2-month follow-up study. Nurs Crit Care 2018;23:299-307.

5. Simeone S, Pucciarelli G, Perrone M, et al. Delirium in ICU patients following cardiac surgery: An observational study. J Clin Nurs 2018;27:1994-2002.

6. De Meyer D, Van Hecke A, Verhaeghe S, et al. PROTECT - Trial: A cluster RCT to study the effectiveness of a repositioning aid and tailored repositioning to increase repositioning compliance. J Adv Nurs 2019;75:1085-98.

7. Lynch S, DeBlieck C, Summers LC, et al. Adolescent stress treatment study: a cluster randomized trial. Clin
Nurs Res 2019;28:795-811.

8. Mak SS. Oncology nursing in Hong Kong: milestones over the past 20 years. Asia Pac J Oncol Nurs 2019;6:10-6.

9. World Medical Association. World Medical Association Declaration of Helsinki: ethical principles for medical research involving human subjects. JAMA 2013;310:2191-4.

10. Sinha B, Sommerfelt H, Ashorn P, et al. Effect of community-initiated kangaroo mother care on postpartum depressive symptoms and stress among mothers of lowbirth-weight infants: a randomized clinical trial. JAMA Netw Open 2021;4:e216040.

11. Spinelli E, Grieco DL, Mauri T. A personalized approach to the acute respiratory distress syndrome: recent advances and future challenges. J Thorac Dis 2019;11:5619-25.

12. Kallet RH, Lipnick MS. Is there still a role for alveolar recruitment maneuvers in acute respiratory distress syndrome? J Thorac Dis 2018;10:85-90.

13. Wang Y, Ju M, Chen C, et al. Neutrophil-to-lymphocyte ratio as a prognostic marker in acute respiratory distress syndrome patients: a retrospective study. J Thorac Dis 2018;10:273-82.

14. Nambiar S, Karippot A, Oliver T. Vedolizumabassociated acute respiratory distress syndrome. Am J Ther 2018;25:e592-3.

15. Schroeder NM, Castiello DR, Siemianowski LA. Inhaled epoprostenol for acute respiratory distress syndrome. Nursing Critical Care 2018;13:6-13.

16. Yin J, Bai CX. Pharmacotherapy for adult patients with acute respiratory distress syndrome. Chin Med J (Engl) 2018;131:1138-41.

17. Lawal O, Muhamadali H, Ahmed WM, et al. Headspace volatile organic compounds from bacteria implicated in ventilator-associated pneumonia analysed by TD-GC/MS . J Breath Res 2018;12:026002.

18. Schwartz J, Taylor M, Heckman T. Preventing probable ventilator-associated pneumonia. Crit Care Nurse 2018;38:E23-4.

19. Metersky ML, Kalil AC. Management of ventilatorassociated pneumonia: guidelines. Clin Chest Med 2018;39:797-808.

20. Bassetti M, Vena A, Castaldo N, et al. New antibiotics for ventilator-associated pneumonia. Curr Opin Infect Dis 2018;31:177-86.

21. Erinc A, Ozcelik HK, Yigitbas BA, et al. Does subglottic secretion drainage prevent ventilatorassociated pneumonia? Eurasian Journal of Pulmonology 
2018;20:122-7.

22. Luyt CE, Hékimian G, Koulenti D, et al. Microbial cause of ICU-acquired pneumonia: hospital-acquired pneumonia versus ventilator-associated pneumonia. Curr Opin Crit

Cite this article as: $\mathrm{Xu} \mathrm{Z}$, Chen J, Xu R. A randomised controlled study: efficacy of ICU nursing risk management combined with the cluster nursing model and its effect on quality of life and inflammatory factor levels of patients with acute respiratory distress syndrome and ventilator-associated pneumonia. Ann Palliat Med 2021;10(7):7587-7595. doi: 10.21037/apm-21-1192
Care 2018;24:332-8.

23. Makris D, Luna C, Nseir S. Ten ineffective interventions to prevent ventilator-associated pneumonia. Intensive Care Med 2018;44:83-6. 